\title{
Article
}

\section{An experimental investigation of burning behaviour of liquid pool fire in corridor- like enclosures}

Chotzoglou, Konstantinos E., Asimakopoulou, Eleni, Zhang, Jianping and Delichatsios, Michael A.

Available at http://clok.uclan.ac.uk/31926/

Chotzoglou, Konstantinos E., Asimakopoulou, Eleni ORCID: 0000-0001-56441372, Zhang, Jianping and Delichatsios, Michael A. (2019) An experimental investigation of burning behaviour of liquid pool fire in corridor-like

enclosures. Fire Safety Journal, 108 . p. 102826. ISSN 0379-7112

It is advisable to refer to the publisher's version if you intend to cite from the work. http://dx.doi.org/10.1016/j.firesaf.2019.102826

For more information about UCLan's research in this area go to http://www.uclan.ac.uk/researchgroups/ and search for <name of research Group>.

For information about Research generally at UCLan please go to http://www.uclan.ac.uk/research/

All outputs in CLoK are protected by Intellectual Property Rights law, including Copyright law. Copyright, IPR and Moral Rights for the works on this site are retained by the individual authors and/or other copyright owners. Terms and conditions for use of this material are defined in the policies page.

\section{CLoK}

Central Lancashire online Knowledge www.clok.uclan.ac.uk

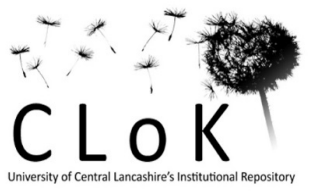




\title{
Experimental investigation of burning behaviour of liquid pool fires in a corridor-like enclosure
}

\begin{abstract}
This work aims to investigate the burning behavior of liquid fuel pool fires in corridor-like enclosures and to identify key factors influencing fire development. A series of experiments is conducted in a $3 \mathrm{~m}$ long medium-scale corridor-facade configuration using ethanol pool fires. To minimize lip effects, a novel fuel supply system has been developed. The influence of fuel surface area and ventilation factor on the fire development is investigated by using two different pan sizes and eight opening dimensions. Experimental results indicate that in corridor-like enclosures the steady-state fuel burning rate in ventilation-controlled conditions corresponds to about $2 / 3$ of that observed in cubic-like enclosures, because the temperature distribution in the enclosure changes from uniform, in cubic-like enclosures, to layered, in corridors. The ventilation coefficient, used to calculate the inflow rate in corridor-like enclosures during post-flashover conditions, is found to decrease as the ventilation factor increases. Subsequently, the heat released inside the corridor was found less than that in cases of burning in cubic-like enclosures. The series of data obtained in the present work can be used for validating engineering correlations and evaluation of CFD models.
\end{abstract}

KEYWORDS: corridor, pool fire, ventilation factor, fuel burning rate, fuel pan size. 


\section{INTRODUCTION}

The study and understanding of the physics in enclosure fires is of considerable importance to the fire safety engineering community, however most of the available data concern cubic-like enclosures [1, 2, 3]. Even though it has been demonstrated that the geometry of an enclosure affects fire development [3, 4, 5, 6], experimental and theoretical aspects of corridor-like enclosures has not been systematically studied. During such scenarios, the mechanism of fire spreading is significantly different compared to cubic-like enclosures as the fire plume impinges on the ceiling resulting in thermal stratification, generation of smoke and toxic gases that are difficult to exhaust due to geometric confinements. Recent major fire disasters occurred in tunnels and corridor-like enclosures [7] highlight the importance of investigating the behaviour of these types of fires to enhance safety assessment and emergency treatment [2, 3]. More specifically, the need to further progress knowledge related to the understanding of the physics of fire development in corridor-like enclosures and the mechanisms that eventually may lead to fire spread in adjacent floors or buildings has been highlighted $[3,8]$.

Most of the studies in enclosure fires are related to under-ventilated conditions, as this region is the worst scenario for enclosure fires usually corresponding to cases where the mass of the pyrolyzed fuel is not completely burned inside the enclosure due to restrictions on the oxygen availability. For under-ventilated enclosure fires, the mass flow rate of the air entering the compartment is a key parameter in determining the maximum heat release rate inside the compartment [2]. The air mass flow rate entering the compartment $\left(\dot{m}_{a}\right)$ can be estimated using the ventilation factor, $A_{v} H_{v}{ }^{1 / 2}[1,2,9]$, where $A_{v}$ and $H_{v}$ are the area and height of the opening respectively. Kawagoe [1] applied the Bernoulli equation to calculate the air inflow through a single moderate opening when under-ventilated conditions prevail and found that $\dot{m}_{a}$ is proportional to $A_{v} H_{v}{ }^{1 / 2}$, as shown in Equation (1), assuming uniform temperature distribution in the interior of a cubic enclosure [1, 10]. He introduced the proportional constant $C$ that is also referred to as the ventilation coefficient and takes values ranging from 0.45 [1] to 0.52 [11] for cubic enclosures with moderate openings. Based on those early research findings, Delichatsios et al. [3] proposed a correction for the expression of $\dot{m}_{a}$ for cubic enclosures, as shown in Equation (2), by subtracting Equation (1) by $0.5 \dot{m}_{T}$, where $\dot{m}_{T}$ is the burning rate of the fuel:

$$
\dot{m}_{a}=\mathrm{C} \times A_{v} H_{v}^{1 / 2}
$$




$$
\dot{m}_{a}=0.5 A_{v} H_{v}{ }^{1 / 2}-0.5 \dot{m}_{T}
$$

Delichatsios and Silcock [12] described the expected behaviour of the steady-state enclosure mass pyrolysis rate over the ventilation factor. They stated that in any enclosure the mass pyrolysis rate increases first as the ventilation factor increases until it reaches a maximum value corresponding to the stoichiometric combustion conditions. After that point, the mass pyrolysis rate decreases with a further increase of the ventilation factor until the ventilation factor becomes infinitely large corresponding to freeburn burning conditions, i.e., for very large ventilation factors, the mass pyrolysis rate becomes constant. In addition, it was found that the air inflow rate depends not only on the ventilation geometry, as was initially assumed by early researchers $[1,10]$, but also on the geometry of the enclosure. Using data from experiments in cubic and corridor enclosures, Delichatsios and Silcock [12] developed the following correlation for fully developed enclosure fires:

$$
\dot{m}_{T}=0.22 \dot{m}_{a}
$$

Further research $[2,4,5,6,13]$ has also shown that the geometry of the enclosure has a significant effect on the burning rate of fuel, $\dot{m}_{T}$, in enclosure fires. Kawagoe [1] proposed and validated using experimental data from the work of [9], that in rectangular configurations, $\dot{m}_{T}$, under ventilation-controlled conditions, can be attained by multiplying $A_{v} H_{v}{ }^{1 / 2}$ by 0.1 , as depicted in Equation (4). However, limited information exists regarding the relation between the burning rate of fuel and the ventilation factor in corridor-like configurations.

$$
\dot{m}_{T}=0.1 A_{v} H_{v}^{1 / 2}
$$

The present research aims at investigating the differences in terms of fire development and burning behaviour between cubic- and corridor-like enclosures. Most of previous work in corridor-like enclosures [e.g., 13, 14, 15] has been performed using gaseous burners, with which the fuel supply rate must be predefined, therefore the interaction between the hot gases and the burning rate cannot be accounted for. However, in real enclosure fires many and different materials can influence the burning rate [16], so configurations without having the ability of controlling the burning rate need to be investigated further. Another reason for studying liquid pool fires is that thermoplastic pool fires which are of great interest in 
an enclosure can also be treated by the same techniques as liquid pool fires [17]. In this work, the same corridor-like enclosure of an aspect ratio of $6: 1[14,18]$ was used but with a more realistic fire source using liquid pool fires. For that reason, a clean sootless fuel to enable identification of the geometric characteristics of externally venting flames, ethanol, has been used and a novel fuel level maintenance system has been designed. Emphasis has been placed on the cooling circuit implemented in the level maintenance system and the use of small pebbles at the interior of the fuel pan that are used to prevent ethanol from boiling and suppress convective motion in the liquid. Two fuel pan sizes of constant fuel surface level and various opening sizes were used to investigate their influence on the burning rate and fire development.

\section{EXPERIMENTAL SETUP}

\subsection{Compartment-façade configuration}

A series of tests was conducted in a corridor-like enclosure having internal dimensions $3 \mathrm{~m}$ x $0.5 \mathrm{~m} \times 0.5$ $\mathrm{m}$. The enclosure was constructed using six $0.5 \mathrm{~m}$ x $0.5 \mathrm{~m}$ cubic boxes and a $1.15 \mathrm{~m}$ x $1 \mathrm{~m}$ façade was attached to the front box, Box A, as indicated in Figure 1, which shows a schematic drawing (side view) of the experimental configuration, depicting also the locations of the measurement devices. The enclosure walls and the façade were lined with non-combustible $40 \mathrm{~mm}$ thick fiber silica-magnesia thermal insulation boards. A door like opening is located in Box A, and the opening dimensions vary for each test case and are summarized in Table 1.

\subsection{Fuel Delivery and Level Maintenance System}

In contrast to previous works using gaseous fuels in corridor-like enclosures $[14,15]$, in this work ethanol pool fire is employed to simulate more realistic fuel sources. A level maintenance system is designed following [19] to keep a constant fuel level (10 mm from the pan's rim) to minimize lip effects and to establish steady-state conditions within the enclosure. Fuel is driven by gravity from the upper tank to the header tank as shown in Figure 1, with any excess fuel flushed to the lower tank. The fuel supply mechanism is placed on a balance to continually monitor the mass loss rate. Two stainless steel circular pans, $6 \mathrm{~cm}$ high and 20 or $30 \mathrm{~cm}$ in diameter, representing radiative, optically thin burning mode regime [20], are used. A water-cooling circuit wrapped around the pan helps retain constant pan temperature to reduce conductive heat losses and thus retain constant burning rates [21, 22]. Small pebbles placed inside 
the pan suppress convective motion in the liquid and excess boiling of the fuel on the surface [23]. The burner is placed on the floor at the center of Box F.

\subsection{Sensors and Data Acquisition System}

A total of thirty-six K-type thermocouples with a bead diameter of $1.5 \mathrm{~mm}$ are used to monitor gas temperatures inside the enclosure every $6 \mathrm{~s}[13,14]$. Six thermocouples positioned, $5 \mathrm{~cm}$ from the side wall, in each Box monitor temperature at 2, 10, 20, 30, 40 and $48 \mathrm{~cm}$ height from the floor as shown in Figure 1. Prior to each fire test, each thermocouple was carefully positioned and aligned; post-test inspection of the measurement locations revealed that most of the thermocouple tips were not shifted during the test. Six steel plate heat flux meters are located in the centerline at the floor level of the corridorlike enclosure [24] and sampling of data was every $3 \mathrm{~s}$. The steel plate meters have spot-welded thermocouples on the unexposed-to-fire surface, and they are embedded into insulation boards. The heat fluxes, using the temperature measurements, are then deduced by solving the three-dimensional conduction equation for both the steel plate and the insulation, as described in detail by Zhang and Delichatsios [25], which also showed that the steel plate heat fluxes gauges produce results in good agreement with those by the Gardon gauges. The whole experimental set-up was placed under a $3 \mathrm{~m} \times 3 \mathrm{~m}$ $1 \mathrm{MW}$ hood to measure heat release rate $(H R R) \dot{Q}_{a c t}$, production of $\mathrm{CO}, \mathrm{CO}_{2}$ and smoke. As mentioned earlier, the mass burning rate was measured by placing the whole fuel delivery system on a balance.

\subsection{Experiments}

In total, sixteen different cases are investigated in the present work, excluding repeatability tests for each case. Table 1 summarizes all the experiment cases presented in this work. The effect of ventilation is investigated by altering the dimensions of the opening. Eight different door-like openings are used in total, with their dimensions shown in Table 1. Two different pan sizes having 20 and $30 \mathrm{~cm}$ diameter were used for determining the influence of pan size to the burning behavior of the pool fires. A liquid pool fuel source represents a realistic fuel as it takes into account the interaction between the rate of fuel supply and heat feedback from the hot gas and compartment walls to the fuel surface, which is essential in the fire development in the enclosure and the subsequent ejection of the flame through the opening (and consequently heat impact on the façade). Results of the current study would not apply to very small pan or jet fires, e.g. $5 \mathrm{~cm} \times 5 \mathrm{~cm}$ relative to current size of the test configuration. The size of the pool fires 
selected in the current study creates a fire behaving as a line fire leaning away from the opening in order to prevent air entrainment from other sides.

\subsection{Experimental Uncertainty}

The ASME methodology is used to estimate the experimental uncertainty as recommended in previous studies [15, 26, 27, 28]. According to this method, the total (expanded) uncertainty, $U_{T}$, of a measurement is the combination of two elementary uncertainties as given by Equation 5. The elementary uncertainty $B_{T}$, is the total 'systematic' uncertainty of the individual 'systematic' uncertainty sources $\left(B_{1,2, \ldots)}\right)$ and is often constant during the experiment. The elementary uncertainty $S_{T}$ is the total 'precision' uncertainty of the individual 'precision' uncertainty sources $\left(S_{1,2, \ldots}\right)$. Both uncertainties are calculated by the root-sumsquare (RSS) method as given in Equations 6 and 7. $k$ 'coverage' factor in Equation 5 depends on the confidence interval $(\sigma)$ needed and is usually of values 2 or 3 ( $2 \sigma$ or $3 \sigma$ ), aiming to achieve a $95 \%$ or $99 \%$ confidence interval respectively. In this work a $k$ factor of valued 2 was used.

$$
\begin{aligned}
& U_{T}= \pm k\left(\left(B_{T} / 2\right)^{2}+S_{T}{ }^{2}\right)^{1 / 2} \\
& B_{T}=\left(B_{1}^{2}+B_{2}^{2}+B_{3}^{2} \ldots\right)^{1 / 2} \\
& S_{T}=\left(S_{1}^{2}+S_{2}^{2}+S_{3}^{2} \ldots\right)^{1 / 2}
\end{aligned}
$$

K-type thermocouples were used for measuring gas temperatures and back-surface temperature of the steel plate heat flux meters. All thermocouples were connected to the data acquisition system via extension wires. Bare-bead thermocouples have no 'precision' error, so $S_{T}=0$ [28]. Regarding systematic uncertainty, thermocouples have standard calibration uncertainty of $\pm 2.2^{\circ} \mathrm{C}$ or $\pm 0.75 \%$ (whichever is greater). Because those values are of $99 \%$ coverage, systematic error of $\pm 1.5^{\circ} \mathrm{C}$ or $\pm 0.5 \%$ for $95 \%$ confidence interval. As reported by Nakos [28] the systematic error is also introduced by the presence of extension wires, which in the present work is assumed to be $\pm 0.5 \%$. Another source of uncertainty in a bare-bead thermocouple is due to radiation, which is determined in this work following [29], who 
introduced a correlation using smaller diameter thermocouples placed close to each main thermocouple used in the experiments. Radiative losses for the thermocouples at the interior of the corridor were also considered via an error of $-6 \%$ to $0 \%$ [15]. An additional $\pm 2 \%$ uncertainty is considered, as a result of other minor errors considered such as those in connection with the acquisition logger, the noise etc [28].

In this work, steel plate heat flux meters originally used by Lee $[13,18]$ were used. They are significantly cheaper but yield results comparable with those by Gardon gauges for enclosure and façade fires [13, 18, 30]. The steel plate meters have spot-welded thermocouples on the unexposed-to-fire surface, and they are embedded into insulation boards. In order to measure the mass loss rate of fuel during burning, the upper and lower tanks of the fuel supply and level maintenance system were placed on a balance. The balance has a maximum load of $36 \mathrm{~kg}$ with $0.2 \mathrm{~g}$ accuracy; mass was logged and recorded every $3 \mathrm{~s}$. The balance used for estimating the mass of the remaining fuel at the fuel delivery system has a standard calibration uncertainty of $\pm 3 \%$. Ethanol used in the experiments is of $\pm 2 \%$ purity uncertainty. Pipe connections and stability of the fuel delivery system with an additional $\pm 3 \%$ random error is reasonably considered.

Heat release rate was measured by the oxygen calorimetry method. The instrumentation has an uncertainty of $\pm 3 \%$ and the flow rate uncertainty is $5 \%$ [31]. In addition, the gases used for the calibration of the hood are of $\pm 5 \%$ accuracy. The balance used for estimating the mass of the remaining fuel at the fuel delivery system has a standard calibration uncertainty of $\pm 0.5 \%$. Ethanol used in the experiments is of $\pm 2 \%$ purity uncertainty. Considering pipe connections and stability of the fuel delivery system, an additional $\pm 3 \%$ random error is reasonably considered. The systematic standard $\left(B_{i}\right)$ and total expanded $\left(U_{t}\right)$ uncertainty is calculated for all components, and estimated values are tabulated in Table 2.

\section{RESULTS AND DISCUSSION}

\subsection{Repeatability tests}

To demonstrate the repeatability of the tests, two representative test cases namely D20W20H20 and D30W50H50 are chosen. Table 3 shows the operational conditions of these test cases. Figure 2 shows comparisons of $\dot{Q}_{a c t}$, and upper layer gas temperature at $2 \mathrm{~cm}$ under the ceiling at Boxes $\mathrm{F}$ and $\mathrm{A}$ for the D20W20H20 and D30W50H50 test cases. Despite minor differences, the trends of experimental data sets 
are almost identical indicating good repeatability of the experiments; similar results are observed in all other cases which are not presented here for brevity.

\subsection{General burning behavior and flame ejection}

Before detailed analysis of the experimental measurement data (HRR, gas temperature, heat fluxes), some general observations are made based on video recordings, mass loss rate $(M L R)$ and $H R R$ measurements. For the lowest ventilation factor (H10W10), fire was self-extinguished as there was not enough fresh air (thus oxygen) reaching the fuel surface located at the rear of the corridor to sustain combustion. As a result, fire could not be sustained for more than $3 \mathrm{~min}$. The same behaviour was observed for both pan sizes.

For low ventilation factors (W15H15, W10H25 and W20H20), burning took place only inside the corridor (i.e., no flames were observed outside the enclosure) and steady-state conditions were established shortly after fire initiation. Another case with no flames ejected through the opening was D20W50H50; burning of this case was like the free-burn case with similar $\dot{Q}_{a c t}$ because the HRR is small and the opening is very large. For the larger openings of W25H25, W30H30, W50H25 and W50H50 flames ejected through the opening before steady burning was achieved. In all cases, except the ones which were self-extinguished and D20W50H50, steady-state conditions (based on $\dot{Q}_{a c t}$ ) were achieved after they became ventilationcontrolled. As the main objective of this work is to investigate ventilation-controlled fires, only these cases are further analyzed in the following sections.

\subsection{Effect of pan size}

Significant differences in the burning behaviour are observed with different fuel pan sizes. To demonstrate the main characteristic stages in the fire growth, the temporal evolution of measured $H R R, \dot{Q}_{a c t}$, and theoretical HRR, $\dot{Q}_{t h}$, are plotted in Figure 3 for two characteristic test cases, namely D30W30H30 and D20W30H30. The maximum theoretical $H R R, \dot{Q}_{t h}$, is calculated using Equation (8) based on the measured mass loss rate and the heat of combustion, $\Delta H_{c}$, of ethanol $(26780 \mathrm{~kJ} / \mathrm{kg})$. The theoretical HRR, $\dot{Q}_{t h}$, was calculated based on the assumption that the factor $C$ is the same as that in a cubic-like enclosure i.e., $C=$

0.5. The maximum $H R R$ inside an enclosure under stoichiometric conditions, $\dot{Q}_{s t, i n}$, can be calculated by 
multiplying $\dot{m}_{a}$ by the heat released by complete combustion of $1 \mathrm{~kg}$ oxygen, which for most fuels is found to be approximately equal to $3000 \mathrm{~kJ} / \mathrm{kg}$ [2].

$$
\begin{aligned}
& \dot{Q}_{t h}=\dot{m}_{T} \Delta H_{c} \\
& \dot{Q}_{a c t}=3000 \times \dot{m}_{a}
\end{aligned}
$$

As shown in Figure 3, the fire behaviour is characterized by three district phases (Regions I, II and III as illustrated in the figures) appearing in succession. Region I corresponds to the fuel-controlled period (growth period), where the combustion efficiency (the ratio between $\dot{Q}_{a c t}$ and $\dot{Q}_{t h}$ ) is close to unity and thus $\dot{Q}_{a c t}$ and $\dot{Q}_{t h}$ are almost equal. In the case with the smaller $20 \mathrm{~cm}$ pan, Region I period is substantially prolonged. This prolongation can be attributed to the radiation feedback to the fuel surface from the flame and the surroundings, which is less and results in smaller burning rates. During Region II, fire gradually becomes ventilation-controlled and $\dot{Q}_{a c t}$ reaches a plateau until flames eject through the opening. Region II corresponds to the steady burning stage before external burning occur and it reveals the interaction between the flame and evaporation of the fuel and the mechanism governing flame movement. It is determined by nearly constant HRR, gas temperature and heat fluxes. This Region II, for which the proposed relations apply, corresponds to underventilated conditions with the unburned fuel not yet to burn at the exterior of the corridor. In test cases with large openings (e.g. W25H25, W30H30, W50H25 and

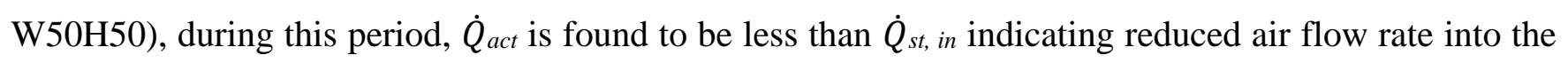
compartment. The fact that $\dot{Q}_{a c t}$ is less than $\dot{Q}_{s t, \text { in }}$ indicates that the factor $C$ for the present configuration is less than 0.5 - the average value of all tests is calculated at 0.38 .

Flames ejection indicates the beginning of Region III, where sustained external burning is observed. The start of Region III is characterized by the appearance of external flames, which was identified from the video recording and indicated by a slight increase of the total HRR. This region provides insights into the characteristics of the ejected flame in terms of heat impact on the façade by measuring flame height and heat fluxes on the façade. In Region III, $\dot{Q}_{a c t}$ continues to increase until a plateau is formed indicating steady state conditions are established. Similar trends in HRR as depicted in Figure 3 are generally observed in other test cases. 
To explain the difference in the $H R R$, upper layer gas temperature histories at a height of $48 \mathrm{~cm}$ for test cases D20W30H30 and D30W30H30 for all Boxes are depicted in Figure 4. During Region I, maximum temperatures are observed in Box $\mathrm{F}$ at the rear of the corridor as the fire is still fuel-controlled. For the case $\mathrm{D} 30 \mathrm{~W} 30 \mathrm{H} 30$, gas temperatures increase at much higher rates as a result of higher $H R R$ and the duration of this region is much shorter compared to D20W30H30. During Region II, maximum temperature is observed in Box E indicating that flames detach from the burner and gradually migrate towards the opening where oxygen availability is increased. At the same time, temperature in Box F decreases reaching a plateau, indicating steady-state conditions. In Region III, flames fill the upper layer of the corridor and appear to be anchored in Box E extending towards the opening, and eventually emerges from the opening when the $H R R$ becomes sufficiently large.

For most of the cases investigated in this work, flames detached from the pan after the initial growth period, moving towards the next box seeking fresh air. For some cases further propagation was followed towards the Box D or C. Beji et al. [24] studied the rate of flame propagation towards the opening in a similar enclosure, by using the gas temperature data inside the corridor. Temperature measurements under the ceiling were used to indicate the presence of the flame. It was then assumed that in any given box, the peak of temperature recorded at the highest location indicated the passing of the flame through that point. Moreover, the detachment of the flames from the burner was confirmed by a sudden decrease of temperature measurement at the top location inside the Box F. Measurements of temperature inside the corridor were taken in locations closer to the one side of the walls and not in the centreline along the corridor. This could introduce some uncertainty, as the fire source was placed on the centreline along the corridor. Similar methodology was also used by [15] and [32]. This behavior is further supported by the top thermocouple readings from all the boxes along the corridor length for the case D30W20H20 as given in Figure 5.

\subsection{Effect of ventilation factor}

To examine the effect of ventilation factor on the burning rate, Figure 6 plots $\dot{m}_{T}$ against $A_{v} H_{v}{ }^{1 / 2}$ both normalized by the fuel surface area, $A_{f}$, for all test cases when the steady state condition is achieved. Additional data for cubic enclosures [33] are also included for comparison. Values for $\dot{m}_{T}$ are taken as the average of those at steady state conditions in Region III. As the ventilation factor increases, the normalized burning rate, $\dot{m}_{T} / A_{f}$, also increases until reaching a maximum value corresponding to the 
transition from ventilation- to fuel-controlled conditions, observed at about $A_{v} H_{v}{ }^{1 / 2} / A_{f}=2$. A further increase in the opening factor results in a decrease in $\dot{m}_{T} / A_{f}$, as the fire becomes fuel-controlled and finally $\dot{m}_{T} / A_{f}$ approaches the free-burn burning rate.

The trend between $\dot{m}_{T} / A_{f}$ and $A_{v} H_{v}^{1 / 2} / A_{f}$ found in this work follows those obtained for cubic enclosures [1, 3]. Using experimental data from [1, 3, 33] for different fuels, Delichatsios et al. [3] found that the slope of the ventilation-controlled regime for cubic enclosures is 0.1, Equation (10). The present data indicate that in corridor-like enclosure a linear relation between $\dot{m}_{T} / A_{f}$ and $A_{v} H_{v}^{1 / 2} / A_{f}$ still exists, as shown in Figure 6. However, the proportional constant is found to be 0.067, Equation (11), which is about $2 / 3$ of the one observed in cubic-like enclosures.

$$
\begin{aligned}
& \frac{\dot{m}_{T}}{A_{f}}=0.1 \frac{A_{v} H_{v}{ }^{1 / 2}}{A_{f}} \\
& \frac{\dot{m}_{T}}{A_{f}}=0.067 \frac{A_{v} H_{v}{ }^{1 / 2}}{A_{f}}
\end{aligned}
$$

Current results based in 6:1 aspect ratio corridor-like experiments, are in accordance with previous experimental studies in corridors $[3,4,5,34]$ demonstrating that the burning rate in corridor-like enclosure is less than that in cubic-like enclosures under ventilation-controlled conditions. This difference was attributed to a decrease of the air inflow rate or the ventilation coefficient, $C$, in corridor-like enclosures [4] and [35]. The typical values for $C$ are 0.45 [1] or 0.5 [2], which have been deduced during postflashover conditions in cubic enclosures with single moderate opening. It is clearly demonstrated that the aspect ratio of the enclosure has an important influence on the stratification or uniform mixing of hot gases, which in turn affects the burning rate. During underventilated conditions, a recirculated volume in created around the fire to which no direct fresh air arrives. The fire is supported by vitiated air and the flow to and from the opening is generated from the developed buoyant field at the end of the fire volume. Thomas et al. [4] and Yii et al. [35] examined the effects of opening dimensions on the air flow rate and concluded that assuming a constant $C$ value overestimates the air inflow rate, especially when the opening width is the same as the full width of the enclosure. Yii et. al. [35] also showed that for large openings air entrainment dominates the vent flows. 
During Region II, all combustion takes place inside the enclosure. The ventilation coefficient can be calculated from the measured HRR in Region $I I$ as $C=\dot{Q}_{a c t} / 3000 A_{v} H_{v}^{1 / 2}$ with the assumption that all oxygen is consumed in the enclosure in this region. This assumption is reasonable as the HRR in this region is nearly constant and external burning occurs after the end of this region. Figure 7 shows the calculated $C$ values for all test cases. It is found that $C$ decreases with a decrease in the ventilation factor, which is in accordance to previous analysis of post-flashover fires $[4,35]$ indicating that $\dot{m}_{a}$ in long enclosures (e.g. corridors) is less than in rectangular enclosures with the same opening geometry. $\dot{Q}_{a c t}$, averaged over Region III, inside the corridor is plotted against the ventilation factor, Figure 8. A linear correlation is found between the average heat released inside the corridor and the ventilation factor. The value of $1110 \mathrm{~kW} / \mathrm{m}^{5 / 2}$ is $26 \%$ lower than the $1500 \mathrm{~kW} / \mathrm{m}^{5 / 2}$ which is widely proposed for cubic like enclosures.

Lower values of both mass pyrolysis rate and mass inflow rate found in corridor-like enclosures compared to cubic enclosures can be attributed to the formation of a two-layer temperature profile in the enclosure. To further support this, vertical distribution of the temperature profiles (time averaged over the steadystate period) inside near the opening (Box A) and at the rear of the corridor (Box F) are plotted in Figures 9 and 10 for all the $20 \mathrm{~cm}$ and $30 \mathrm{~cm}$ diameter pan cases. In Box A, fresh air entraining through the opening results in lower temperatures compared to that in Box F. For the cases with greater ventilation factors, temperature stratification is more intense, resembling clearly a two-layer zone distribution as the mass inflow rate through the opening is essentially entrainment driven. As the ventilation factor decreases, the interface between the hot and cold layers descends towards the floor and more mixing occurs, approaching the well-mixed scenario [1]. In these cases, the inflow rate inside the enclosure is restricted by the vent opening and the coefficient value, $C$, tends to the one proposed for cubic-like enclosures, namely 0.5. Temperatures seem more uniform close to the fire source, indicating more mixing occurring close to the pool fire. The present results clearly illustrate that temperature distribution in corridor enclosures cannot be considered uniform even under ventilation-controlled conditions, as is usually done for cubic enclosures [1], and thus Equation (1) should not be used in such fire scenarios. The opening size also has an importance influence on the temperature distribution inside the corridor - for small openings the vertical temperature distribution tends to uniform; whereas for larger openings it becomes layered.

Temperature measurements are further supported by the heat fluxes measurements on the corridor floor. Figures 11 and 12 show the time averaged heat fluxes over the steady state period plotted against the 
distance from the opening for all the $20 \mathrm{~cm}$ and $30 \mathrm{~cm}$ diameter pan cases respectively. There is no data for Box $\mathrm{E}$ in two of the cases as the meters were damaged during the test. The highest heat flux is found for the cases with the larger ventilation factors, as they have the highest HRRs. Higher heat fluxes for increased ventilation factor could also be attributed to the prolonged ventilation-controlled Region III period. For all cases, the highest heat flux is in either Box D or Box F, which is consistent with the fact that maximum temperatures are at these locations as shown in Figure 4. Higher temperatures of the hot gas layer results in higher heat flux on the floor and as a result enhance the evaporation of the liquid fuel. With a further decrease in the distance from the opening, heat flux decreases.

\subsection{Combustion efficiency}

Combustion efficiency over the steady-state period based on the theoretical and the actual HRR is plotted versus the ventilation factor in Figure 13. It is observed that, the combustion efficiency of the fuelcontrolled cases using the small pan (D20W15H15 and D20W50H50) was of the highest value, approaching unity. A higher value, 0.7 was also calculated for the fuel-controlled case D30W50H50. However, all the ventilation-controlled cases were of combustion efficiency less than 0.7. The overall combustion efficiency of the test case D20W15H15 with ventilation factor of 0.01 is close to unity. In this case no flames appeared out of the corridor and burning is taking place only inside Box F. Data for the cases having W10H10 opening are not plotted, since the fire was self-extinguished.

It was observed that for the ventilation-controlled cases of both pan sizes, as the ventilation factor increases, the combustion efficiency increases too. This is attributed to the fact that more oxygen is available for combustion as more fresh air enters the corridor when increasing the opening size.

It is interesting now to show the combustion efficiency against the equivalence ratio, $\varphi$. As reported in [2] and [36] $\varphi$ defines the ratio of the fuel mass flux, $\dot{m}_{T}$, to the oxygen mass flux entering the enclosure, $\dot{m}_{\mathrm{O}_{2}}$, divided by the fuel-to-oxygen stoichiometric ratio of the fuel, S. Based on the maximum heat released inside an enclosure, $\varphi[2]$ is calculated [13, 15, 18] as follows in Equation 12.

$$
\varphi=\dot{Q}_{t h} / \dot{Q}_{s t, i n}=\dot{m}_{T} \Delta H_{c} /\left(3000 \times C \times A_{v} \sqrt{H_{v}}\right)
$$


When $\varphi$ exceeds unity, the fire is considered ventilation-controlled; whereas when $\varphi$ is less than unity, the fire is fuel-controlled. The data for all the cases when fire sustained are plotted in Figure 14. The data obtained show a good correlation between the combustion efficiency and the equivalence ratio; combustion efficiency reduces as the equivalence ratio increases from 1 to 2.5. The highest combustion efficiency was found for the fuel-controlled cases. For most of the ventilation-controlled cases the combustion efficiency is between 0.5 and 0.67 .

\section{CONCLUSIONS}

The focus of the current study is the investigation of the effect of realistic fire load and ventilation conditions on the burning rate and fire development at a medium-scale corridor-like enclosure. In that scope, an extended series of medium-scale fire tests was performed using a liquid pool fire located at the rear of a corridor-like enclosure. Current work specially addressed the effect of ventilation conditions and use of realistic fuel source on fire development. For that reason, a clean sootless fuel, ethanol, has been used and a novel fuel level maintenance system has been designed. Emphasis has been placed on the cooling circuit implemented in the level maintenance system and the use of small pebbles at the interior of the fuel pan that are used to prevent ethanol from boiling and suppress convective motion in the liquid. Two pan sizes and eight opening sizes (thus ventilation factors) were used. The main conclusions of this work are:

1. For most cases, three distinct burning regions (Region I, II and III) have been observed, corresponding respectively to fuel-controlled, ventilation-controlled and steady-state burning (Figure 3). The duration of each regions depends on both the pan size and ventilation factor. In Region II, the heat release rate is nearly constant, and flame detaches from the burner moving towards the opening. The transition from Region II to Region III is indicated by the flame emerging from the opening. In Region III, the HRR continues to increase until a steady state is established.

2. For the cases when ventilation-controlled conditions are achieved, the normalized steady state mass burning rate, $\dot{m}_{T} / A_{f}$, is found to increases linearly with the normalized ventilation factor, $A_{v} H_{v}^{1 / 2} / A_{f}$, which is consistent with previous findings with cubic-like enclosures $[1,2,3]$. However, the proportional constant is found to be about $2 / 3$ of that observed in cubic-like enclosures (Figure 6).

3. HRR inside the corridor for the ventilation-controlled cases was found lower than the value $1500 A_{o} H_{o}{ }^{1 / 2}$ used for rectangular compartments. For the current experiments the proportional factor was 
found to be 1110 instead of $1500 \mathrm{~kW} / \mathrm{m}^{5 / 2}$. This is because the ventilation coefficient, $C$, decreases as the ventilation factor increases; in the present study was found to be approximately 0.39 for most of the cases. Current results suggest that inflow air entering the corridor is less than the one given by Equation 1 $(C=0.50)$.

4. The lower value of mass pyrolysis rate found in the current study for corridor enclosures compared to the value proposed in literature for cubic-like enclosures (see discussion related to Equations 10 and 11) are due to the formation of a non-uniform temperature profile inside the enclosure. Thus, it is suggested that the well-mixed fire environment [1] does not properly describe the temperature formation inside the corridor and should be used cautiously.

5. The combustion efficiency during steady-state period was found to increase proportionally to the ventilation factor, as the availability of oxygen for combustion is increased. In addition, a linear relationship between the combustion efficiency and the equivalence ratio exists for combustion efficiency values between 1 and 2.5 .

The present results can not only be applied to liquid pool fires scenarios in corridors, tunnels or other configurations having similar length to width aspect ratios but also be used to develop and validate engineering correlations and CFD models. Future research is planned to extend the experimental database by including experiments to investigate the effect of different liquid fuels, ventilation layouts (e.g. forcedventilation conditions), aspect ratios of the enclosure, fuel type and its distribution within the enclosure. More detailed information regarding velocity, gas and smoke concentration at the interior would also further enhance the understanding of the phenomena involved. 


\section{REFERENCES}

[1] K. Kawagoe, Fire Behaviour in Rooms, Report 27, Building Research Institute, Tokyo, 1958.

[2] M. Hurley, D. Gottuk, J. Hall, K. Harada, E. Kuliqowiski, M. Puchovsky, J. Torero, J. Watts, C. Wieczorek, SFPE Handbook of fire protection engineering, 4th Edition, National Fire Protection Association, Quincy, Massachusetts, USA, 2016.

[3] M.A. Delichatsios, G.W.H. Silcock, X. Liu, M. Delichatsios, Y.P. Lee, Mass pyrolysis rates and excess pyrolysate in fully developed enclosure fires, Fire Saf. J., 39 (2004) 1- 21, https://doi.org/10.1016/j.firesaf.2003.07.006

[4] I.R. Thomas, I.D. Bennetts, Fires in enclosures with single ventilation openings-comparison of long and wide enclosures, Fire Saf. Sci.-Proc. Int. Symp., International Association for Fire Saf. Sci., 6 (1999) 941-952, https://doi.org/10.3801/IAFSS.FSS.6-941

[5] S. Miyazaki, Y. Watanabe, An experimental study on fire phenomena of liquid fuel in a small-sized tunnel burning behaviour of n-heptane (Part 1), paper B-14 and An experimental study on fire phenomena of liquid fuel in a small-sized tunnel relation between inside temperature of the tunnel and burning rate of n-heptane (Part 2), paper A-15, 1998.

[6] M.A. Delichatsios, Enclosure and façade fires: Physics and applications, Proceedings of the $11^{\text {th }}$ International Symposium on Fire Saf. Sci., 2014, https://doi.org/10.3801/IAFSS.FSS.11-3

[7] L.H. Hu, R. Huo, W.K. Chow, Studies on buoyancy-driven back-layering flow in tunnel fires, Exp. Therm. Fluid Sci. 32 (2008) 1468-1483, https://doi.org/10.1016/j.expthermflusci.2008.03.005

[8] E.H. Yii, Modelling the effects of fuel types and ventilation openings on post-flashover compartment fires, PhD Thesis, University of Canterbury, Canterbury, New Zealand, 2002.

[9] P.H. Thomas, A.J.M. Heselden, M. Law, Fully developed compartment fires: two kinds of behaviour, Fire Research Technical Paper No. 18, HMSO, London, 1967.

[10] J.A. Rocket, Fire induced gas flow in an enclosure, Comb. Sci. and Tech., 12 (1976) 165-175. https://doi.org/10.1080/00102207608946717

[11] K.D. Steckler, J.G. Quintiere, W.J. Rinkinen W.J., Flow induced by fire in a compartment, Proceedings of the $19^{\text {th }}$ International Symposium on Comb., (1982) 913-920, https://doi.org/10.1016/S0082-0784(82)80267-1 
[12] M.A. Delichatsios, G.W.H . Silcock, Fully involved enclosure fires: Effects of fuel type, fuel area and geometry, Proceedings of the $7^{\text {th }}$ International Symposium of Fire Saf. Sci., (2002) 59-73, https://doi.org/10.3801/IAFSS.FSS.7-59

[13] Y.P. Lee, Heat fluxes and flame in external facades from enclosure fires, PhD thesis, FireSERT, University of Ulster, Jordanstown, UK, 2006.

[14] T. Beji, Theoretical and experimental investigation on soot and radiation in fires, $\mathrm{PhD}$ thesis, FireSERT, University of Ulster, Jordanstown, UK, 2009.

[15] S. Ukleja, Production of smoke and carbon monoxide in under-ventilated enclosure fires, $\mathrm{PhD}$ thesis, FireSERT, University of Ulster, Jordanstown, UK, 2012.

[16] D. Drysdale, An introduction to fire dynamics, third edition, J. Wiley and Sons Ltd, Sussex, England, 2011.

[17] V. Babrauskas, Free burning fires, Fire Saf. J., 11 (1986) 33-51, https://doi.org/10.1016/0379$\underline{7112(86) 90051-2}$

[18] Y.P. Lee, M.A. Delichatsios, G.W.H. Silcock, Heat fluxes and flame heights in facades from fires in enclosures of varying geometry, Proceedings of the Combustion Institute, 31:2 (2007) 2521-2528. https://doi.org/10.1016/j.proci.2006.08.033

[19] A.R. Hall, Pool Burning: A Review, Report No. AD0781347, Rocket Propulsion Establishment: Westcott, 1972.

[20] V. Babrauskas, Estimating large pool fire burning rates, Fire Technol. 19 (1983) 251-261. https://doi.org/10.1007/BF02380810

[21] V.I. Blinov, G.N. Khudyakov, Diffusion burning of liquids, Report No. AERDL-T-1490-A, Army Engineer Research and Development Labs Fort Belvoir VA, 1961.

[22] A. Vali, D.S. Nobes, L.W. Kostiuk, Effects of altering the liquid phase boundary conditions of methanol pool fires, Experim. Thermal and Fluid Sci. 44 (2013) 786-791, https://doi.org/10.1016/j.expthermflusci.2012.09.023.

[23] A. Luketa, Assessment of simulation predictions of hydrocarbon pool fire tests, Report No. SAND2010-2511, Sandia National Laboratories, 2010. 
[24] T. Beji, S. Ukleja, J. Zhang, M.A. Delichatsios, Fire behaviour and external flames in corridor and tunnel-like enclosures, Fire Mater. 36 (2012) 636-647, https://doi.org/10.1002/fam.1124

[25] J. Zhang, M.A. Delichatsios, M.A., Determination of the convective heat transfer coefficient in threedimensional inverse heat conduction problems, Fire Saf. J. 44 (2009) 681-690, https://doi.org/10.1016/j.firesaf.2009.01.004

[26] E.K. Asimakopoulou, K. Chotzoglou, D.I. Kolaitis, M.A. Founti, Characteristics of externally venting flames and their effect on the façade: A detailed experimental study, Fire Technol. 52 (6) (2016) 2043-2069, https://doi.org/10.1007/s10694-016-0575-5

[27] R.H. Dieck, Measurement Uncertainty Models, in ISA Transactions, 36(1) (1997) 29-35, https://doi.org/10.1016/S0019-0578(97)00004-9

[28] J.T. Nakos, Uncertainty Analysis of Thermocouple Measurements Used in Normal and Abnormal Thermal Environment Experiments at Sandia's Radiant Heat Facility and Lurance Canyon Burn Site, Report No. SAND2004-1023, Sandia National Laboratories, 2004.

[29] S. Brohez, C. Delvosalle, G. Marlair, A two-thermocouples probe for radiation corrections of measured temperatures in compartment fires. Fire Saf. J., 39 (2004), 399-411, https://doi.org/10.1016/j.firesaf.2004.03.002

[30] P. Tofilo, M.A. Delichatsios, G.W.H. Silcock, T.J. Shields, Wall Heat Fluxes in Enclosure Fires, $6^{\text {th }}$ Asia-Oceania Symposium on Fire Science \& Technology (2004) 108-119.

[31] Dark Star Research Ltd.

[32] A. Pearson, J. Most, D. Drysdale, Behaviour of a confined fire located in an unventilated zone. Proceedings of the Combustion Institute, 31:2 (2007) 2529-2536, https://doi.org/10.1016/j.firesaf.2004.03.002

[33] M.L. Bullen, P.H. Thomas, Compartment fires with non-cellulosic fuels, Proceedings of $17^{\text {th }}$ International Symposium on Combustion, Combustion Institute, Leeds, England, 1979, https://doi.org/10.1016/S0082-0784(79)80108-3

[34] G.M.E. Cooke, Tests to determine the behavior of fully-developed natural fires in a large compartment, Fire and Risk Science Fire Note 4, Building Research Establishment Ltd., 1998.

[35] E.H. Yii, C.M. Fleischmann, A.H. Buchanan, Vent flows in fire compartments with large openings. J. of Fire Prot. Eng., 17:3 (2007) 211-237, https://doi.org/10.1177/1042391507069634 
[36] W.M. Pitts, Global equivalence ratio concept and the formation mechanisms of carbon monoxide in enclosure fires. Progress in Energy and Comb. Sci., 21:3 (1995) 197-237, https://doi.org/10.1016/0360-1285(95)00004-2 
NONMENCLATURE

\begin{tabular}{lll}
\hline Symbol & Units & Description \\
\hline$A_{v}$ & $\left(\mathrm{~m}^{2}\right)$ & Area of the opening \\
$A_{f}$ & $\left(\mathrm{~m}^{2}\right)$ & Area of the fuel \\
$B_{T}$ & $(-)$ & Total systematic uncertainty \\
$B_{i}$ & $(-)$ & Systematic standard uncertainty \\
$C$ & $(-)$ & Ventilation coefficient \\
$H_{v}$ & $(\mathrm{~m})$ & Height of the opening \\
$\dot{Q}_{a c t}$ & $(\mathrm{MW})$ & Measured hear release rate \\
$\dot{Q}_{s t, i n}$ & $(\mathrm{MW})$ & Hear release rate in stoichiometric conditions \\
$\dot{Q}_{t h}$ & $(\mathrm{MW})$ & Theoretical hear release rate \\
$k$ & $(-)$ & Coverage factor \\
$\dot{m}_{a}$ & $(\mathrm{~kg} / \mathrm{s})$ & Air mass flow rate entering the compartment \\
$\dot{m}_{O 2}$ & $(\mathrm{~kg} / \mathrm{s})$ & Oxygen mass flow rate entering the compartment \\
$\dot{m}_{T}$ & $(\mathrm{~kg} / \mathrm{s})$ & Burning rate of fuel \\
$R H$ & $(\%)$ & Relative humidity \\
$S$ & $(-)$ & Fuel-to-oxygen stoichiometric ratio \\
$S_{i}$ & $(-)$ & Precision uncertainty source \\
$S_{T}$ & $(-)$ & Total precision uncertainty \\
$T_{a m b}$ & $\left({ }^{\circ} \mathrm{C}\right)$ & Ambient temperature \\
$t_{d u r}$ & $(\mathrm{~s})$ & Experiment duration \\
$U_{t}$ & $(-)$ & Total expanded uncertainty \\
$W_{v}$ & $(\mathrm{~m})$ & Width of the opening \\
$\Delta H_{c}$ & $(\mathrm{~kJ} / \mathrm{kg})$ & Heat of combustion \\
$\sigma$ & $(-)$ & Confidence interval \\
$\eta$ & $(-)$ & Combustion efficiency \\
$\varphi$ & $(-)$ & Equivalence ratio \\
\hline Acronym & &
\end{tabular}

Acronyms

HRR Heat release rate

MLR Mass loss rate 
RSS Root-sum-square method 


\section{FIGURE CAPTIONS}

Figure 1: Schematic drawing of the experimental facility and sensor locations.

Figure 2: Time evolution of heat release rate $\left(\dot{Q}_{\text {act }}\right)$ and upper hot gas layer temperature in the repeatability tests for D2OW20H20 and D30W30H30 test cases.

Figure 3: Temporal evolution of $\dot{Q}_{a c t}$ and $\dot{Q}_{t h}$ for D30W30H30 and D20W30H30 test cases.

Figure 4: Upper hot gas layer temperatures at each Box for test cases D30W30H30 (left) and D20W30H30 (right).

Figure 5: Temporal evolution temperatures at $2 \mathrm{~mm}$ from the ceiling in all boxes along the corridor for D30W20H20 test case.

Figure 6: Normalized values of $\dot{m}_{T}$ against $A_{v} H_{v}{ }^{1 / 2}$ for cubic- [20] and corridor-like enclosures in Regime III.

Figure 7: Ventilation coefficient $C$ for each test case against $A_{v} H_{v}^{1 / 2}$.

Figure 8: Linear correlation between the heat released inside the corridor and the ventilation factor.

Figure 9: Time averaged over the steady state period gas temperature at the interior of the corridor enclosure for all $20 \mathrm{~cm}$ pan test cases, in Box A (left) and Box F (right).

Figure 10: Time averaged over the steady state period gas temperature at the interior of the corridor enclosure for all for all $30 \mathrm{~cm}$ pan test cases, in Box A (left) and Box F (right). 
Figure 11: Time averaged over the steady state period heat flux values at the floor of the corridor enclosure for all $20 \mathrm{~cm}$ pan test cases.

Figure 12: Time averaged over the steady state period heat flux values at the floor of the corridor enclosure for all $30 \mathrm{~cm}$ pan test cases.

Figure 13: Combustion efficiency versus the ventilation factor for the cases that fire sustained and pool fire was placed at the rear end of the corridor.

Figure 14: Combustion efficiency versus the equivalence ratio for the cases that fire sustained and pool fire was placed at the rear end of the corridor. 


\section{TABLE CAPTIONS}

Table 1. Opening dimensions and ventilation factors of the openings studied.

Table 2. Summary of measurement uncertainty components.

Table 3. Summary of the operational conditions of the selected test cases for repeatability. 